\title{
Morphological features of the ventral tegmental area: a brainstem structure related to attention deficit hyperactivity disorder
}

\author{
Ayşegül Güngör Aydın $^{1,2}$ (D), Esat Adıgüzel ${ }^{1,2}$ (D) \\ ${ }^{1}$ Department of Neuroscience, Institute of Health Sciences, Pamukkale University, Denizli, Turkey \\ ${ }^{2}$ Department of Anatomy, School of Medicine, Pamukkale University, Denizli, Turkey
}

\begin{abstract}
Attention deficit hyperactivity disorder (ADHD) is the most common behavioral disorder of the childhood and more interest is raised by clinical investigators nowadays. In spite of being the most studied neurobehavioral condition in child psychiatry, the pathophysiology of ADHD remains elusive. The ventral tegmental area (VTA) has been implicated in the etiology of ADHD. This part of the midbrain needs to be investigated further due to its complex cytoarchitecture and connectivity in order to gain insight into the neurobiology of ADHD. In this review, we will first briefly explain the history of the VTA researches and then summarize the anatomical features and connectivity of this region.
\end{abstract}

Keywords: attention deficit hyperactivity disorder; dopamine; mesocortical pathway; ventral tegmental area

Anatomy 2019;13(1):66-70 @2019 Turkish Society of Anatomy and Clinical Anatomy (TSACA)

\section{Introduction}

Nowadays the ventral tegmental area (VTA) has become the focus of a major research area as being involved in the mechanism of attention deficit hyperactivity disorder (ADHD). On the basis of neurophysiological theories, the atypical development of the connectivity or activity among the midbrain, prefrontal cortex (PFC) and ventral striatum play a key role in the etiopathogenesis of ADHD ${ }^{[1,2]}$ Fronto-subcortical circuits in these structures are rich in catecholamines such as dopamine (DA) and noradrenaline (NA). ${ }^{[3,4]}$ Therefore, DA and NA dysfunctions have long been implicated in the etiology of ADHD. ${ }^{[5,6]}$ It is currently hypothesized that the symptoms of ADHD (inattention, hyperactivity and impulsivity) are due to the dysfunctions of the mesocortical dopaminergic pathway which plays a critical role in the various circuits of the PFC. ${ }^{[7]}$

VTA is a major structure of the mesocorticolimbic dopamine (DA) pathway that involves in executive function, attention and reward-related cognition. ${ }^{[8,9]}$ In fact, dopaminergic neurons are aggregated in two neighboring midbrain regions; VTA and substantia nigra pars compacta $(\mathrm{SNc}) .{ }^{[10]}$ However, the firing and projection patterns of neurons located in these two neighboring regions are different from each other. ${ }^{[11,12]}$ These molecular, anatomic and electrophysiologic differences, are specifically important in understanding the intrinsic distinctness of the dopaminergic VTA neurons. ${ }^{[1,1,14]}$

Starting with the first study by Soemmerring ${ }^{[15]}$ in 1792 , research has been increasingly focused on cytoarchitectural features of the midbrain nuclei. Cytoarchitectural studies have provided valuable information for the functional demarcation of catecholaminergic neurons in the brainstem.

After demarcation of these nuclei, it has been shown that $\mathrm{SN}$ and VTA are associated with movement disorders and psychotic diseases, respectively. ${ }^{[1,1,1]}$

The immunohistochemical revelation of tyrosine hydroxylase $(\mathrm{TH})$, the rate-limiting enzyme of DA synthesis, was a breakthrough in the identification of dopaminergic cells. ${ }^{[18]}$ Immunocytochemical studies have revealed clusters of dopaminergic neurons and three main 
nuclei in the midbrain have been identified: retrorubral field (A8), SN (A9), and VTA (A10). The A8 neurons are generally considered as the extension of the A9 cell group, since the rostral and ventral portion of the A8 cell group can not be clearly differentiated from the contiguous A9 neurons of the caudal and lateral SN. The A8 neurons are also continuous with the caudal and lateral portions of the A10 cell group. ${ }^{[19]}$ The A9 neurons correspond to the nigral DA-cells, most of which are localized in the SNc, but also in the substantia nigra pars reticularis $(\mathrm{SNr})$ and to a lesser extent in the substantia nigra pars lateralis $(\mathrm{SNl})$. The A9 neurons project predominately to the dorsolateral striatum which corresponds to putamen and part of caudate nucleus in man and plays a crucial role in the control of movement and degenerates preferentially in Parkinson's disease ${ }^{[2,21]}$ A10 neurons are localized in VTA and give rise to mesocorticolimbic system. The mosocorticolimbic system innervates the frontal cortex, ventral striatum (nucleus accumbens), the bed nucleus of the stria terminalis and amygdala complex, and is also involved in motivation, reward and sustained attention processes. ${ }^{[19,22]}$

In terms of relative proportion of $\mathrm{TH}$-immunopositive cells, the A8 cells account for about 5\%, and the A9 and A10 cells account for about $95 \%$, with a more or less equal distribution in rodents. It was reported that in the rat TH immunohistochemistry reveals 15,000-20,000 dopaminer- gic neurons on each side of the midbrain tegmentum, and about 9000 of these cells belong to the VTA. ${ }^{[19]}$ Furthermore, subdivisions of VTA have been defined in some species, including human, rat, cat, and monkey. ${ }^{[23]}$ The subgroups of VTA have been termed with different names for approximately 200 years. Tsai's descriptive anatomical study on the brain of the opossum is the keystone study about VTA structures. The ventromedial mesencephalic tegmentum was also first described and named as VTA by Tsai. ${ }^{[2]}$ Phillipson has described five distinct nuclei: three of them are located in the midline or medial position (nucleus linearis rostralis, nucleus linearis caudalis, and nucleus interfascicularis) and two of them are described as lateral nuclei, nucleus paranigralis and nucleus parabrachialis pigmentosus. ${ }^{[23,25,26]}$

\section{Cytoarchitectural Description of Components}

Since the boundaries of VTA are not distinct, it is difficult to define its components. Therefore, it is necessary to use neuron-specific immunohistochemical staining for their identification. In Nissl stained sections, neurons of VTA were distinguishable from the red nucleus dorsally, and separated from the interpeduncular nucleus ventrally. ${ }^{[25,26]}$ However, this adjacency of these structures shows differences in the sections of midbrain from caudal to rostral (Figure 1). In terms of ease of understanding, the local-

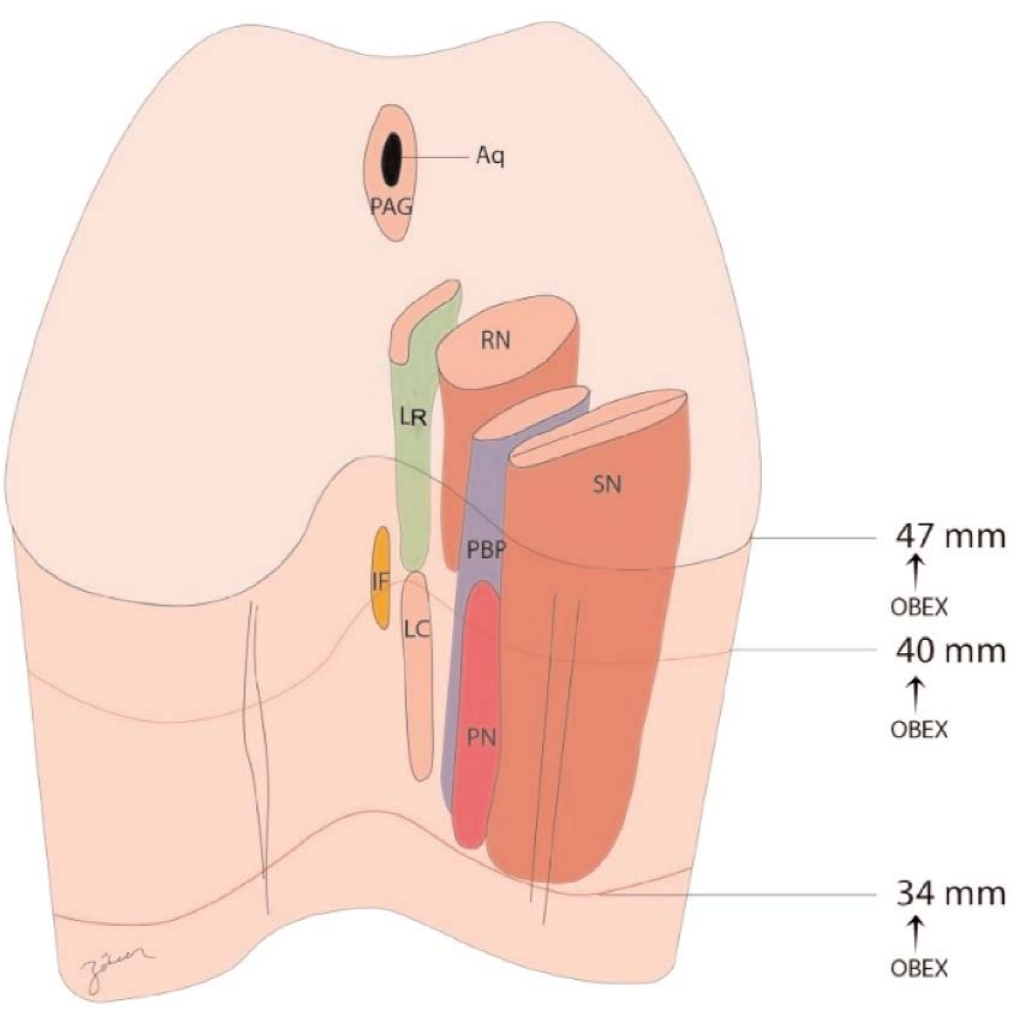

Figure 1. Schematic illustration of the human midbrain displaying VTA nuclei. The localizations of the nuclei are approximately displayed by using the Atlas of the Human Brainstem by Paxinos and Huang as reference. Aq: aquaduct; IF: nucleus interfascicularis; LC: nucleus linearis caudalis/centralis; LR: nucleus linearis rostralis; PAG: periaquductal gray; PN: nucleus paranigralis; PBP: nucleus parabrachialis pigmentosus; RN: red nucleus; SN: substantia nigra. Illustration design: Esat Adıgüzel; digitalization: C. Gökçen Köseli. [Color figure can be viewed in the online issue, which is available at www.anatomy.org.tr] 
ization of these structures were discussed by using the Atlas of the Human Brainstem by Paxinos and Huang that takes obex as a reference point. ${ }^{[27]}$ The order of the structures is as follows; the most caudal VTA subdivision is the nucleus PN (paranigralis), seen $34 \mathrm{~mm}$ rostral from the obex. Nucleus PBP (parabrachialis pigmentosus), nucleus LC (linearis raphe caudalis/centralis), red nucleus (RN), IF (interfascicularis), and LR (linearis raphe rostralis) start appearing from obex at $35 \mathrm{~mm}, 35 \mathrm{~mm}, 38 \mathrm{~mm}, 40 \mathrm{~mm}$ and $40 \mathrm{~mm}$, respectively; LC, IF and PN disappear at 40 $\mathrm{mm} 41 \mathrm{~mm}$ and $41 \mathrm{~mm}$, respectively. LR and PBP continue from obex up to $47 \mathrm{~mm}$ rostral ${ }^{[27]}$ (Figure 1). IF is located in the midline, LR and LC are in the paramedian zone, and others (PN, PBP) are located more laterally in humans. The LC curves lateral of PAG dorsally and extends to interpeduncular fossa ventrally. It neighbors the RN and PBP laterally. ${ }^{[19]}$

In the region of the human VTA, neuron sizes range from 10 to $53 \mu \mathrm{m} .{ }^{[19]} \mathrm{PN}$ neurons are small to medium in size, stellate, round, fusiform or spindle in shape, and lie ventrally in the VTA. The orientation of PN neurons in coronal sections is horizontal. In contrast, PBP neurons lies dorsally in the VTA. Some of these neurons are small, but most of them are medium-sized, and are more randomly arranged dorsal to the PN with no preferential orientation. ${ }^{[26]}$ The IF neurons are usually very small particularly at the anterior pole, fusiform and oriented mediolaterally. LR and LC neurons are very variable based on their size, shape, and are often oriented ventrodorsally. They are clearly isolated from other neurons of the VTA because of the presence of neuromelanin pigment. The largest neurons of the five component nuclei are found in LR. ${ }^{[19,25]}$

Five component nuclei contain roughly 690,000 neurons, and approximately $80 \%$ of these neurons are dopaminergic in human. ${ }^{[10,19]}$ However, these neurons are different from each other due to their properties. After Carlsson first developed the histofluorescence microscopic method that allowed sensitive visualization of a neurotransmitter in the neuron, the first detailed paper displaying the distribution of catecholamine (CA) containing neurons in the rat brain was published. ${ }^{[28-30]} \mathrm{A}$ new nomenclature for the monoamine-containing neuron groups was adopted based on Dahlström and Fuxe observations with CA histofluorescence. The CA class of monoamines was named "A" for the descriptive purposes. They identified twelve groups of catecholaminergic neurons (A1-A12) distributed from the medulla oblongata to the hypothalamus. ${ }^{[30]}$

The dopamine (DA) containing pathways of the midbrain were divided as A8, A9 and A10 neurons. A9 neu- rons are located in the $\mathrm{SNc}$, whereas the $\mathrm{A} 8$ neurons are located dorsal and caudal to the SN. The A10 neurons are found in the VTA with some of them extend into the structures located at the midline. ${ }^{[31]}$ The A10 neurons projecting from the VTA (five component nuclei) to the limbic and cortical areas along mesolimbic and mesocortical pathways. ${ }^{[32]}$ Dopaminergic axon branches of the mesocortical pathways within the cortex reach more than one cortical areas. ${ }^{[33]}$ Neocortex is extensively innervated by midbrain dopaminergic projections in humans. These projections to the PFC arise mostly from the VTA, mesocortical dopaminergic system, and play a critical role in executive functions, attention and motor components of the behavior. ${ }^{[34,35]}$ Mesocortical dopaminergic system has received considerable attention due to its involvement in a range of psychological processes and neuropsychiatric diseases such as ADHD. ${ }^{[36,37]}$

Despite the presence of subdivisions within the VTA, their respective functions have not yet been clarified. This is more likely due to the difficulty in selectively manipulating these different groups of neurons, their relatively small size, proximity and mostly shared neurochemistry. However, behavioral evidence supports the presence of a major antero-posterior heterogeneity within the $\mathrm{VTA}^{[38]}$ In addition, this anteroposterior heterogeneity concerns the functionality as one of the most important symptoms of ADHD, the locomotor activity. ${ }^{[3]}$ Accumulating evidence indicates that subdivisions of the VTA are also physiologically and characteristically heterogeneous. One group of neurons is centered in the medial VTA and projects to the medial PFC. The nucleus accumbens medial shell and core and basolateral amygdala are smaller and have fewer and shorter dendritic branches as compared to the lateral VTA neurons which are projecting to more lateral parts of the nucleus accumbens and ventrolateral caudat-putamen. ${ }^{[13,40-42]}$ While the medial subdivisions of the VTA are fast-firing, display higher baseline activity profiles and have low DA transporter (DAT)/TH mRNA ratios, lateral VTA neurons have a slow firing pattern and express DAT more robustly. ${ }^{[13,41]}$ Uniquely, VTA neurons that project to the medial PFC lack D2 receptor-mediated auto-inhibition and display lower levels of D2. ${ }^{[13]}$ These neurons also have a very low expression of DAT when compared with mesolimbic projecting neurons. ${ }^{[43,44]}$ Indeed, it has been shown that the medial PFC maintains higher concentrations of DA for longer amounts of time compared with the striatum. ${ }^{[45,46]}$ Because of the decreased uptake for DA in VTA-medial PFC, DA neurons could have functional importance for the DA in working memory and executive functions in the cortex. 


\section{Conclusion and Perspectives}

Psychostimulants affecting dopaminergic systems are the most frequently prescribed treatments for ADHD. The mechanism of these stimulants is to increase the DA level in the PFC by inhibiting the dopamine transporters. ${ }^{[36]}$ Since VTA is the major dopamine source of the PFC, it has been that VTA plays an important role in ADHD. Nevertheless, the neuronal pathophysiology of ADHD is obscure, and further researches are needed.

We have reviewed the subdivisions of VTA neurons and highlighted the necessity for a better understanding of these subdivisions of VTA in terms of functionality. We would argue that the depth of our understanding of the functional role of the subdivisions of VTA will continue to increase, only if accompanied by continued elucidation of its neuroanatomical relationship. However, the subdivions of VTA sends functionally distinct DA projections to its targets. Recent advances in optogenetic techniques, projection- and cell-specific molecular profiling have opened up new avenues into addressing these issues. To better understand how these subdivisions of VTA convey it to their target sites, it is necessary to determine the organization of connectivity in the VTA and the functional nature of the synapses that are established by these neurons in upstream brain structures. The subdivions of VTA cell maps and identifying their connectivity pattern will be useful for future neurobiological studies on ADHD.

\section{Acknowledgement}

The authorsare thankful to Gökçen Köseli for digitalization of the drawing.

\section{References}

1. Schultz W. Dopamine neurons and their role in reward mechanisms. Curr Opin Neurobiol 1997;7:191-7.

2. Matthews M, Nigg JT, Fair DA. Attention deficit hyperactivity disorder. Curr Top Behav Neurosci 2014;16:235-66.

3. Ikemoto S, Panksepp J. The role of nucleus accumbens dopamine in motivated behavior: a unifying interpretation with special reference to reward-seeking. Brain Res Rev 1999;31:6-41.

4. Faraone SV, Biederman J. Neurobiology of attention-deficit hyperactivity disorder. Biol Psychiatry 1998;44:951-8.

5. Pliszka SR. The neuropsychopharmacology of attentiondeficit/hyperactivity disorder. Biol Psychiatry 2005;57:1385-90.

6. Curatolo P, D'Agati E, Moavero R. The neurobiological basis of ADHD. Ital J Pediatr 2010;36:79.

7. Blum K, Chen ALC, Braverman ER, Comings DE, Chen TJH, Arcuri V, Blum SH, Downs BW, Waite RL, Notaro A, Lubar J, Williams L, Prihoda TJ, Palomo T, Oscar-Berman M. 2017 Attention-deficit-hyperactivity disorder and reward deficiency syndrome. Neuropsychiatr Dis Treat 2008;4:893-918.
8. Sesack SR, Grace AA. Cortico-basal ganglia reward network: microcircuitry. Neuropsychopharmacology 2010;35:27-47.

9. Malenka RC, Nestler EJ, Hyman SE. Molecular neuropharmacology: A foundation for clinical neuroscience. New York, NY: McGrawHill Medical; 2009. p. 516.

10. Swanson $L W$. The projections of the ventral tegmental area and adjacent regions: a combined fluorescent retrograde tracer and immunofluorescence study in the rat. Brain Res Bull 1982;9:321-53.

11. Margolis EB, Hjelmstad GO, Bonci A, Fields HL. Kappa-opioid agonists directly inhibit midbrain dopaminergic neurons. J Neurosci 2003;23:9981-6.

12. Margolis EB, Lock H, Hjelmstad GO, Fields HL. The ventral tegmental area revisited: is there an electrophysiological marker for dopaminergic neurons? J Physiol 2006;577:907-24.

13. Lammel S, Hetzel A, Häckel O, Jones I, Liss B, Roeper J. Unique properties of mesoprefrontal neurons within a dual mesocorticolimbic dopamine system. Neuron 2008;57:760-73.

14. Beier KT, Steinberg EE, DeLoach KE, Xie S, Miyamichi K, Schwarz L, Gao XJ, Kremer EJ, Malenka RC, Luo L. Circuit architecture of VTA dopamine neurons revealed by systematic input-output mapping. Cell 2015;162:622-34.

15. Faull RLM, Taylor DW, Carman JB. Soemmerring and the substantia nigra. Medical History 1968;12:297-9.

16. 16-Stevens JR. An anatomy of schizophrenia? Arch Gen Psychiatry 1973;29:177-89.

17. van Domburg PHMF, ten Donkelaar HI. The human substantia nigra and ventral tegmental area. A neuroanatomical study with notes on aging and aging diseases. Adv Anat Embryol Cell Biol 1991;121:1-32.

18. Ljungdahl A, Hökfelt T, Goldstein M, Park D. Retrograde peroxidase tracing of neurons combined with transmitter histochemistry. Brain Res 1975;84:313-9.

19. Björklund, A, Lindvall O. Dopamine containing systems in the CNS. In: Björklund A, Hökfelt T, editors. Handbook of chemical neuroanatomy. Vol. 2. Classical transmitters in the CNS, Part 1. Amsterdam: Elsevier; 1984. p. 55-122.

20. Damier P, Hirsch EC, Agid Y, Graybiel AM. The substantia nigra of the human brain. II. Patterns of loss of dopamine-containing neurons in Parkinson's; disease. Brain 1999;122:1437-48.

21. Lewis DA, Sesack SR. Dopamine systems in the primate brain. In: Bloom FE, Björklund A, Hökfelt T, editors. Handbook of chemical neuroanatomy. Vol. 13. Amsterdam: Elsevier; 1997. p. 263-375.

22. Kalivas PW, Nakamura M. Neural systems for behavioral activation and reward. Curr Opin Neurobiol 1999;9:223-7.

23. Halliday GM, Törk J. Comparative anatomy of the ventromedial mesencephalic tegmentum in the rat, cat, monkey and human. J Comp Neurol 1986;252:423-45.

24. Tsai C. The optic tracts and centers of the opossum. Didelphis virginiana. J Comp Neurol 1925; 39:173-216.

25. Phillipson, OT. The cytoarchitecture of the interfascicular nucleus and ventral tegmental area of Tsai in the rat. J Comp Neurol 1979a; 187:85-98.

26. Phillipson, OT. A Golgi study of the ventral tegmental area of Tsai and interfascicular nucleus in the rat. J Comp Neurol 1979b;187:99116.

27. Paxinos G, Huang XF. Atlas of the human brainstem. San Diego, CA: Academic Press; 1995. 
28. Falck B, Hillarp NA, Thieme G, Torp A. Fluorescence of catechol amines and related compounds condensed with formaldehyde. Brain Res Bull 1982;9:11-5.

29. Carlsson A, Falck B, Hillarp NA. Cellular localization of brain monoamines. Acta Physiol Scand Suppl 1962;56:1-28.

30. Dahlström A, Fuxe K. Evidence for the existence of monoaminecontaining neurons in the central nervous system. I. Demonstration of monoamines in the cell bodies of brain stem neurons. Acta Physiol Scand Suppl 1964;232:1-55.

31. Oades RD, Halliday GM. Ventral tegmental (AlO) system: neurobiology. 1. Anatomy and connectivity. Brain Res 1987;434:117-65.

32. Bentivoglio M, Morelli $M$. The organisation and circuits of mesencephalic dopaminergic neurons and the distribution of dopamine receptors in the brain. In: Dunnett SB, Bentivoglio, Björklund A, Hökfelt $\mathrm{T}$, editors. Handbook of chemical neuroanatomy (Dopamine). Vol. 21. London: Elsevier; 2005. p. 1-109.

33. Albanese A, Bentivoglio M. The organization of dopaminergic and non-dopaminergic mesencephalocortical neurons in the rat. Brain Res 1982;238:421-5.

34. Williams SM, Goldman-Rakic PS. Widespread origin of the primate mesofrontal dopamine system. Cereb Cortex 1998;8:321-45.

35. Lewis DA, Sesack SR, Levey AI, Rosenberg DR. Dopamine axons in primate prefrontal cortex: specificity of distribution, synaptic targets, and development. Adv Pharmacol 1998;42:703-6.

36. Engert V, Pruessner JC. Dopaminergic and noradrenergic contributions to functionality in ADHD: the role of methylphenidate. Curr Neuropharmacol 2008;6:322-8.

37. Volkow ND, Wang GJ, Fowler JS, Ding YS. Imaging the effects of methylphenidate on brain dopamine: new model on its therapeutic actions for attention-deficit/hyperactivity disorder. Biol Psychiatry 2005;57:1410-5.
38. Ikemoto S, Murphy JM, McBride WJ. Self-infusion of GABA(A) antagonists directly into the ventral tegmental area and adjacent regions. Behav Neurosci 1997;111:369-80.

39. Bolanos CA, Neve RL, Nestler EJ. Phospholipase C gamma in distinct regions of the ventral tegmental area differentially regulates morphine-induced locomotor activity. Synapse 2005;56:166-9.

40. Tan Y, Brog JS, Williams ES, Zahm DS. Morphometric analysis of ventral mesencephalic neurons retrogradely labeled with fluoro-gold following injections in the shell, core and rostral pole of the rat nucleus accumbens. Brain Res 1995;689:151-6.

41. Margolis EB, Mitchell JM, Ishikawa J, Hjelmstad GO, Fields HL. Midbrain dopamine neurons: projection target determines action potential duration and dopamine $\mathrm{D}(2)$ receptor inhibition. J Neurosci 2008;28:8908-13.

42. Lammel S, Ion DI, Roeper J, Malenka RC. Projection-specific modulation of dopamine neuron synapses by aversive and rewarding stimuli. Neuron 2011;70:855-62.

43. Sesack SR, Hawrylak VA, Matus C, Guido MA, Levey AI. Dopamine axon varicosities in the prelimbic division of the rat prefrontal cortex exhibit sparse immunoreactivity for the dopamine transporter. J Neurosci 1998;18:2697-708.

44. Lewis DA, Melchitzky DS, Sesack SR, Whitehead RE, Auh S, Sampson A. Dopamine transporter immunoreactivity in monkey cerebral cortex: regional, laminar, and ultrastructural localization. J Comp Neurol 2001;432:119-36.

45. Moghaddam B, Berridge CW, Goldman-Rakic PS, Bunney BS, Roth RH. In vivo assessment of basal and drug-induced dopamine release in cortical and subcortical regions of the anesthetized primate. Synapse 1993;13:215-22.

46. Garris PA, Collins LB, Jones SR, Wightman RM. Evoked extracellular dopamine in vivo in the medial prefrontal cortex. J Neurochem 1993;61:637-47.

Correspondence to: Ayşegül Güngör Aydın Department of Anatomy, School of Medicine, Pamukkale University, Denizli, Turkey Phone: 902582962459

e-mail: aysglgngr@gmail.com; agungor@pau.edu.tr

Conflict of interest statement: No conflicts declared.

This is an open access article distributed under the terms of the Creative Commons Attribution-NonCommercial-NoDerivs 3.0 Unported (CC BY-NCND3.0) Licence (http://creativecommons.org/licenses/by-nc-nd/3.0/) which permits unrestricted noncommercial use, distribution, and reproduction in any medium, provided the original work is properly cited. Please cite this article as: Güngör Aydın A, Adıgüzel E. Morphological features of the ventral tegmental area: a brainstem structure related to attention deficit hyperactivity disorder. Anatomy 2019;13(1):66-70. 